\title{
Injury of Partial Colon Obstruction in Colonic Interstitial Cells With/Without Interstitial Cells of Cajal
}

TO THE EDITOR: Colonic interstitial cells of Cajal (ICC) networks are constituted as submuscular plexus, myenteric plexus, and intramusculature plexus. These networks of ICC play their different roles in the colon. For example, intramusculature plexus-ICC is responsible for relaxation of colonic smooth muscles in which ICC interplay the signal between nitrergic nerve and the muscle. The alteration or ablation of such motility inhibitory device may result in colonic motility function disorder and/or anatomic injury. ${ }^{1-3}$

Wang et al ${ }^{4}$ recently published a study "Colonic dysmotility in murine partial colonic obstruction due to functional changes in interstitial cells" in which a partial colon obstruction mouse model was evaluated. After 7 days of partial colon obstruction an astonishing observation was found, ie, colonic smooth muscle layers were increased as hypertrophic in both weight and thickness, compared to the control model at the same length scale (Fig. 1A and 1B). However, within such increased muscle layer there was decreased ICC density with Kit and Ano1 proteins' expression (Fig. 1C and 1D). Interestingly, the type of cell increased in the muscle layer was platelet-derived growth factor receptor- $\alpha$ (Pdgfra) accompanied with its expressed ionic channel-SK3 (Fig. 1E and $1 \mathrm{~F}$ ). ${ }^{4}$

Here, what was found by Wang et $\mathrm{al}^{4}$ in the study is apparently new but there are some vaguenesses to be clarified such as interstitial cells and ICC, colonic migrating motor complexes (CMMCs), and slow waves. Firstly, whole muscle extracts would have contained protein from all cells of the layer including smooth muscle cells (SMCs), PDGFR $\alpha^{+}$, and neurons with which western blot for SK3 protein expression was not proper for PDGFR $\alpha^{+}$cells, unless measured in cells sorted, or someway purified. Secondly, electrophysiological measurements have shown that a specific antagonist of SK chan- nels on CMMCs which cannot be accounted for the targeting on $\mathrm{PDGFR}_{\alpha}{ }^{+}$cells since SMCs and neurons are also enriched with SK3. We provide here an example as shown in Figure 2 to illustrate isolated slow wave which may support the study of Wang et al. ${ }^{4}$ Slow wave activity was recorded in normal mice under the similar conditions as described by Wang et al, ${ }^{4}$ except for the presence of tetrodotoxin (TTX) $1 \mu \mathrm{M}$ (neuronal activity blocker) and nifedipine $1 \mu \mathrm{M}$ (L-type calcium channel blocker inhibiting muscular activity). This is the classic activity for slow waves reflecting ICC unique activity. Briefly, the slow wave was performed by extracellular recording in an organ bath $\left(37^{\circ} \mathrm{C}\right)$ by using $10-\mathrm{cm}$ tubular segment of proximal colon. The segment was flushed gently with Krebs solution. The oral end of the segment was mounted onto the tube for perfuse-in and distal end was attached to the tube for perfuse-out, in which the fluid was from oral to distal consistently and maintained the pressure for distension. Recording electrode was attached to the serosal side of the segment by suction. The signal from the electrode was amplified through a Grass ink writing amplifier-recorder. The segment was equilibrated in Krebs solution $\left(37-38^{\circ} \mathrm{C}\right.$ ) saturated with 95\% $\mathrm{O}_{2}$ and $5 \% \mathrm{CO}_{2}$ for 1 hour. Activity was evoked and maintained by distension in presence of nifedipine $1 \mu \mathrm{M}$ and TTX $1 \mu \mathrm{M}$. A regular slow wave shown in Figure 2A as a control to contrast to the following treatments. As shown in Figure 2B, application of NPPB (5-Nitro-2-[3-phenylpropylamino] benzoic acid, $10 \mu \mathrm{M}$ ) inhibited slow wave, which is consistent to the study. ${ }^{4}$ As shown in Figure $2 \mathrm{C}$, the application of apamin $(1 \mu \mathrm{M})$ did not affect the slow wave frequency illustrating that ICC are without SK3 channel, consistent with other studies. ${ }^{5,6}$ Note, the slow wave amplitude shown is above the half of average, thus not counted as change. 
A

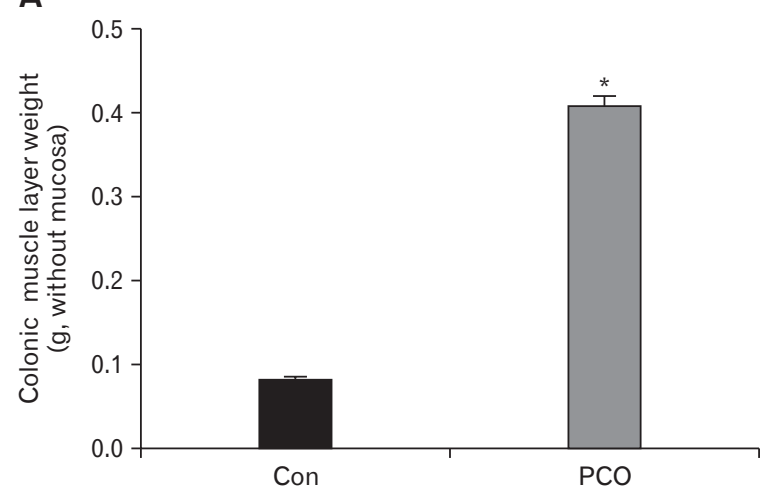

C

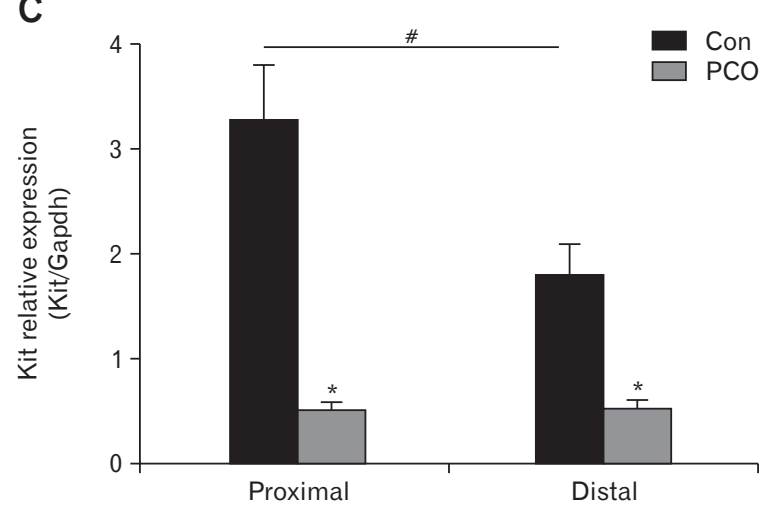

E

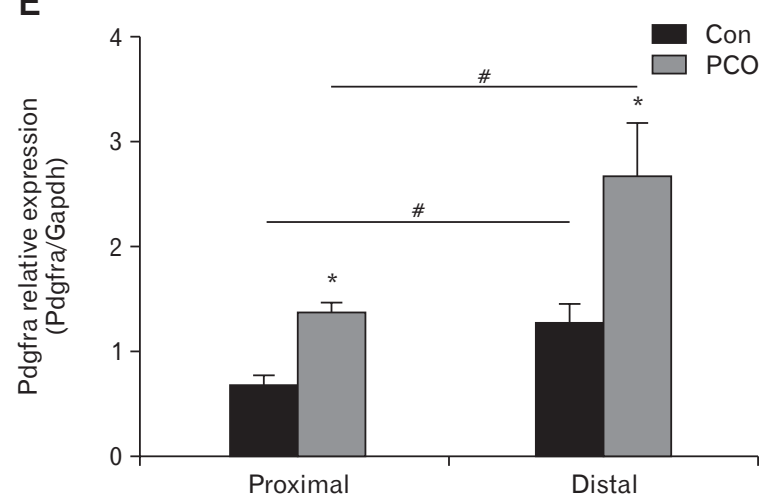

B

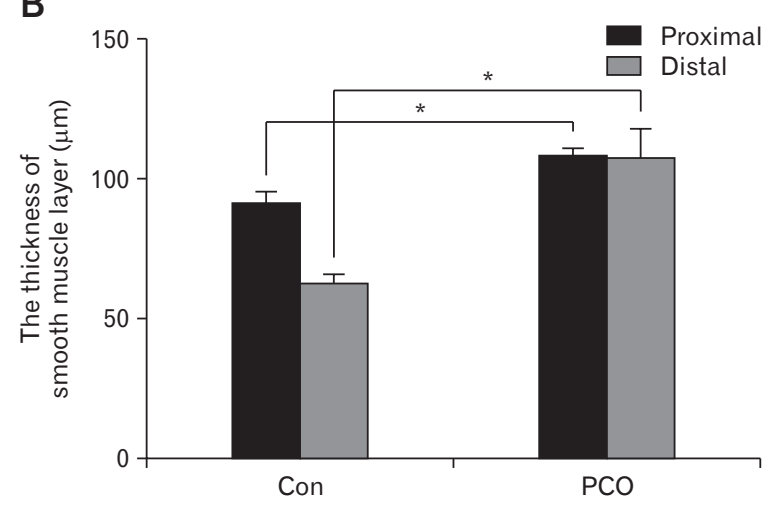

D

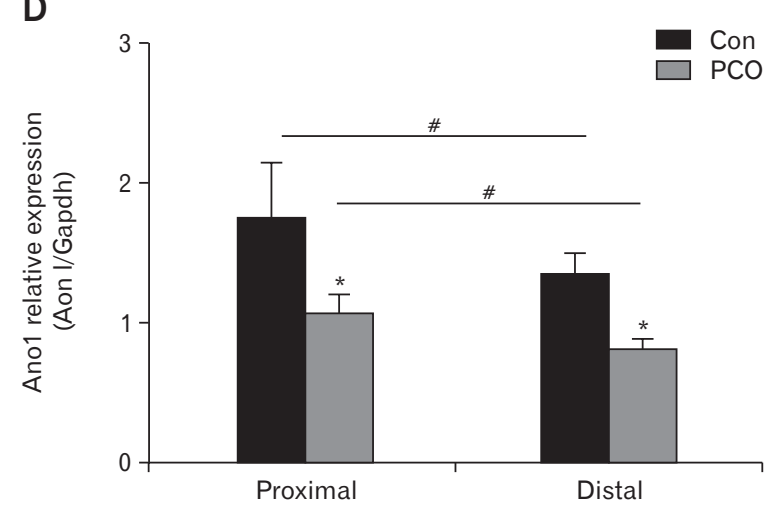

$\mathbf{F}$

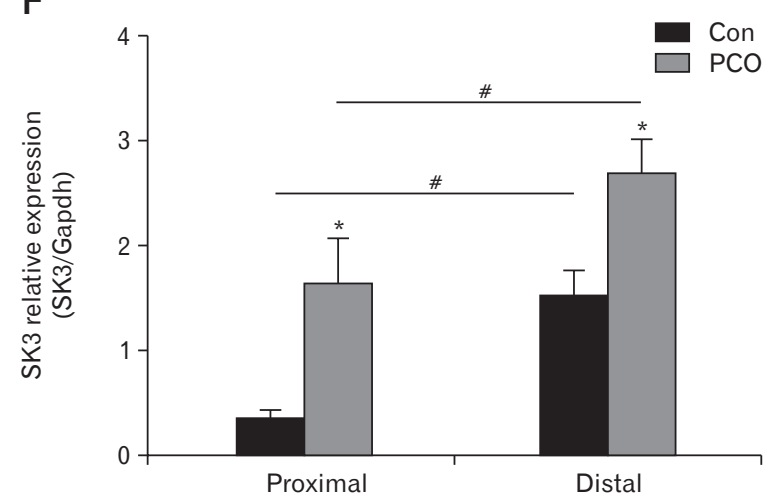

Figure 1. Anatomic changes by comparison of the weight $(\mathrm{A})$ and thickness $(\mathrm{B})\left(\mathrm{n}=7,{ }^{*} \mathrm{P}<0.05\right)$. Comparing the expression of Kit $(\mathrm{C})$ and Ano1 (D) in the colonic muscle layers using densitometric quantification $\left(\mathrm{n}=6\right.$; ${ }^{*} \mathrm{P}<0.05$, partial colon obstruction [PCO] vs control [Con]; ${ }^{\#} P<0.05$, proximal vs distal). Western blot analysis of platelet-derived growth factor receptor- $\alpha$ (Pdgfra) $(\mathrm{E})$ and SK3 (F) (n $=6$; ${ }^{*} P<0.05$, $\mathrm{PCO}$ vs Con; ${ }^{\#} \mathrm{P}<0.05$, proximal vs distal). All figures are reorganized from the study by Wang et al. ${ }^{4}$

Jianlin Lv, ${ }^{1}$ Meng Xia, ${ }^{2}$ Zengzi Zhou, ${ }^{3}$ and Zhenbin $\mathrm{Hu}^{1 *}$ ${ }^{I}$ The First Affiliated Hospital of Guangxi University of Chinese Medicine, Nanning; Guangxi, China; ${ }^{2}$ Guangxi university of Chinese Medicine, Nanning; Guangxi, China; and ${ }^{3}$ The 3rd Xiangya Hospital, Central South University, Changsha, Hunan, China

1. Huizinga JD, Zhu Y, Ye J, Molleman A. High-conductance chloride channels generate pacemaker currents in interstitial cells of Cajal. Gastroenterology 2002;123:1627-1636.
2. Zhu Y, Golden CM, Ye J, Wang XY, Akbarali HI, Huizinga JD. ERG $\mathrm{K}^{+}$currents regulate pacemaker activity in ICC. Am J Physiol Gastrointest Liver Physiol 2003;285:G1249-G1258.

3. Koh SD, Sanders KM, Ward SM. Spontaneous electrical rhythmicity in cultured interstitial cells of Cajal from the murine small intestine. J Physiol 1998;513(Pt 1):203-213.

4. Wang Q, Zang J, Huang X, Lu H, Xu W, Chen J. Colonic dysmotility in murine partial colonic obstruction due to functional changes in interstitial Cells. J Neurogastroenterol Motil 2019;25:589-601. 

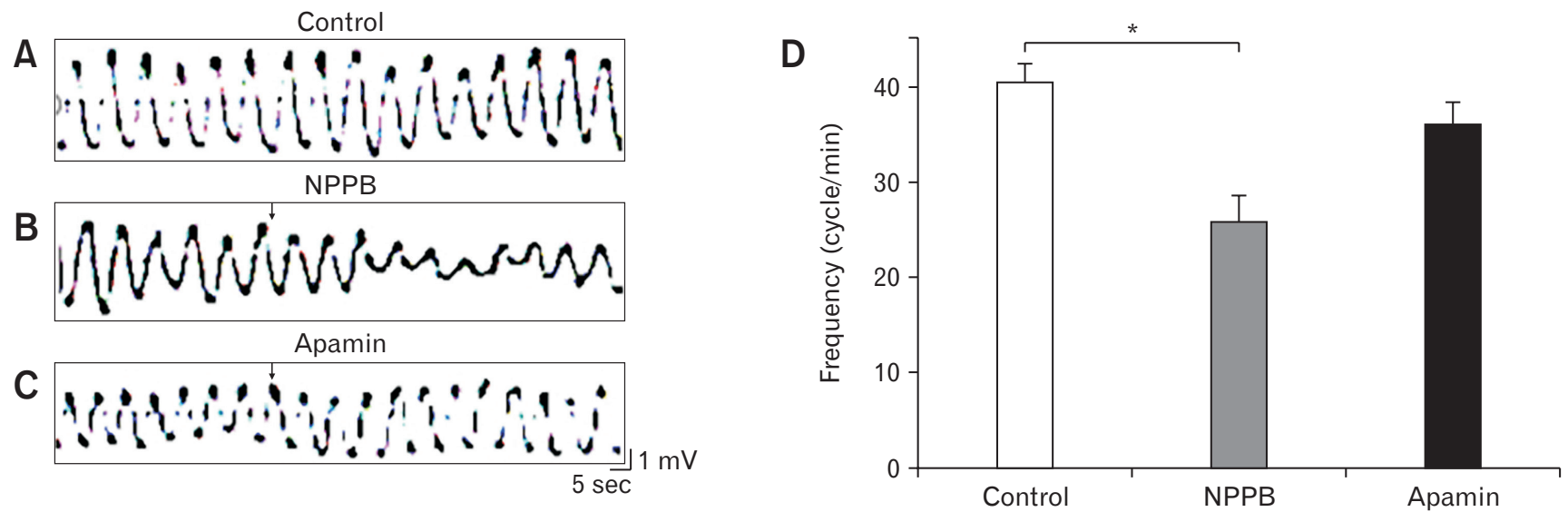

Figure 2. Slow wave activity affected by NPPB (5-Nitro-2-[3-phenylpropylamino] benzoic acid), not by Apamin. (A) Normal slow-wave activity in control condition. (B) Slow-wave activity in application of NPPB $(10 \mu \mathrm{M})$. (C) Slow-wave activity in application of Apamin $(1 \mu \mathrm{M})$. Note a complete washout was through between 2 applications. (D) A summary of slow wave frequency changes from A-C ( $\left.\mathrm{n}=4,{ }^{*} P<0.05\right)$.

5. Lee H, Koh BH, Peri LE, Sanders KM, Koh SD. Functional expression of SK channels in murine detrusor PDGFR ${ }^{+}$cells. J Physiol 2013;591:503-513.

6. Zhu Y, Ye J, Huizinga JD. Clotrimazole-sensitive $\mathrm{K}^{+}$currents regulate pacemaker activity in interstitial cells of Cajal. Am J Physiol Gastrointest Liver Physiol 2007;292:G1715-G1725.

\section{Financial support: None.}

\section{Conflicts of interest: None.}

Author contributions: Jianlin Lv and Meng Xia performed the experiment and contributed equally to this study; Zengzi Zhou involved manuscript and revising; and Zhenbin Hu designed the study. 